\title{
Correction to: Changes in spatio-temporal distribution of AgMERRA-derived agro-climatic indices and agro-climatic zones for wheat crops in the northeast Iran
}

\author{
Fatemeh Yaghoubi ${ }^{1}$. Mohammad Bannayan ${ }^{1}$. Ghorban-Ali Asadi ${ }^{1}$
}

Published online: 4 November 2021

(c) ISB 2021

Correction to: International Journal of Biometeorology https://doi.org/10.1007/s00484-021-02156-3
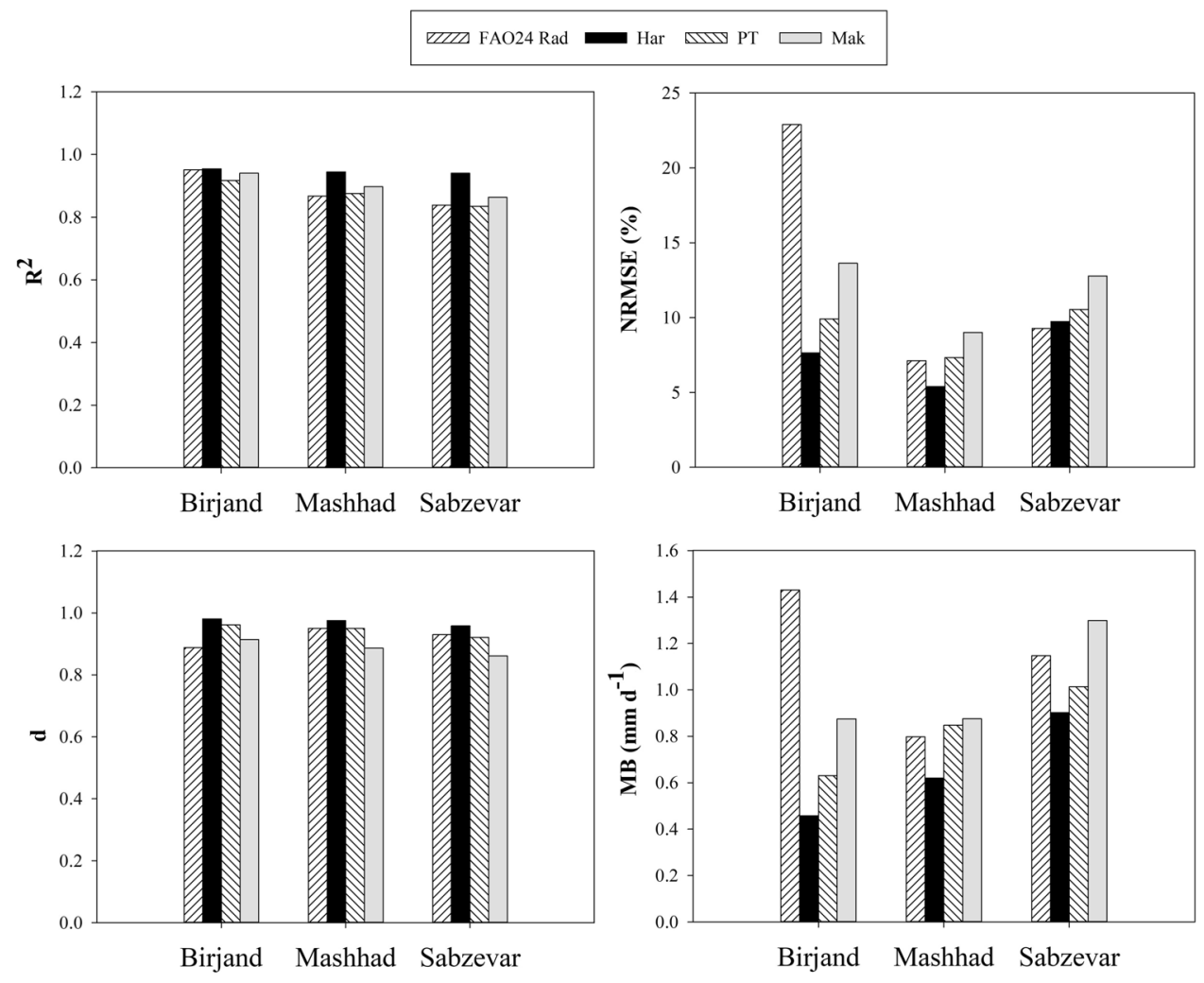

The original article can be found online at https://doi.org/10.1007/ The original article was published with an un-edited lower s00484-021-02156-3. resolution figure (Fig. 3). Below is the correct figure.

Mohammad Bannayan

banayan@um.ac.ir

The original article has been corrected.

Fatemeh Yaghoubi

fa.yaghoubi@mail.am.ac.ir

Ghorban-Ali Asadi

asadi@um.ac.ir

1 Faculty of Agriculture, Ferdowsi University of Mashhad,

P.O. Box 91775-1163, Mashhad, Iran 